\title{
Double Tube Drainage for the Management of Large Proximal Jejunal Blowout Perforation - A Novel Proposition
}

\author{
Ashish Vora ${ }^{1}$, Peeyush Kesarwani², Rahul Pawar ${ }^{3}$, Rajesh Sharma ${ }^{4}$, Manoj Kela ${ }^{5}$ \\ ${ }^{1}$ Department of Surgery, Shri Aurobindo Institute of Medical Sciences \& PGI, Indore, Madhya Pradesh, India. \\ ${ }^{2}$ Department of Surgery, Shri Aurobindo Institute of Medical Sciences \& PGI, Indore, Madhya Pradesh, India. \\ ${ }^{3}$ Department of Surgery, Shri Aurobindo Institute of Medical Sciences \& PGI, Indore, Madhya Pradesh, India. \\ ${ }^{4}$ Department of Surgery, Shri Aurobindo Institute of Medical Sciences \& PGI, Indore, Madhya Pradesh, India. \\ ${ }^{5}$ Department of Surgery, Shri Aurobindo Institute of Medical Sciences \& PGI, Indore, Madhya Pradesh, India.
}

\section{INTRODUCTION}

Isolated Jejunal peroration in a case of blunt trauma abdomen is less encountered and variably dealt with. Being rare, its diagnosis itself is very late clinically and hence carries very high rate of morbidity \& mortality. Here we attempted a novel technique to manage the dreaded proximal intestinal leak and avoid stoma at a very proximal site. High output proximal fistula that follows leak is still a nightmare for the resident.

Isolated Jejunal blowout injuries are easily missed and diagnosed late. The management involves a primary repair which has a very high risk of leak. This further increases the financial burden and emotional trauma, to the patient \& family, as it involves multiple surgeries and prolonged hospital stay following leak and / or high output proximal fistula. This can be avoided by addition of a retrograde duodenostomy to secure the anastomosis without much expense. This reduces the overall stay and expense. Bile collected from the Retrograde Duodenostomy tube was further utilized and replaced to the patient, thus alleviating the need for total parenteral nutrition also. Here we present our technique.

\section{PRESENTATION OF CASE}

A 25-year-old male presented to the emergency department with a history of fall from a truck 2 days back. He was treated at a local hospital and was referred to our center. On arrival, the general condition was poor with BP of 80/50 mmHg pulse rate of 96 bpm and RR of 30 cycles/per min. Patient also gave history of not passing stools or flatus since last $24 \mathrm{hrs}$.

On per abdominal examination guarding and tenderness was present in the epigastric region with generalized board like rigidity. X-ray abdomen standing showed free gas under right hemi-diaphragm (fig. 1). Ultrasonography showed free fluid in the peritoneal cavity with internal echoes.

\author{
Corresponding Author: \\ Dr. Ashish Vora, \\ \#302, Akanksha Apartments, \\ Second Floor, SAIMS \& PGI, \\ Indore-453555, Madhya Pradesh, India. \\ E-mail: ashishvora.ms@gmail.com
}

DOI: 10.14260/jemds/2020/499

How to Cite This Article:

Vora A, Kesarwani P, Pawar R, et al. Double tube drainage for the management of large proximal jejunal blowout perforation - a novel proposition. J. Evolution Med. Dent. Sci. 2020;9(32):2307-2309, DOI: $10.14260 /$ jemds/2020/499

Submission 04-05-2020,

Peer Review 29-06-2020,

Acceptance 06-07-2020,

Published 10-08-2020.

Copyright (C) 2020 JEMDS. This is an open access article distributed under Creative Commons Attribution License [Attribution 4.0 International (CC BY 4.0)] 


\section{DISCUSSION OF MANAGEMENT}

Patient was started on I.V. antibiotics and resuscitated. Emergency laparotomy was planned.

\section{Intraoperative Procedure}

A large Jejunal grade III (according to AAST) perforation involving the $2 / 3^{\text {rd }}$ circumference was seen with gross contamination of the peritoneal cavity.[1] After refreshing the mucosal edges blowout was closed with 3-0 polyglactin 910 and lambert sutures were placed with 2-0 silk.
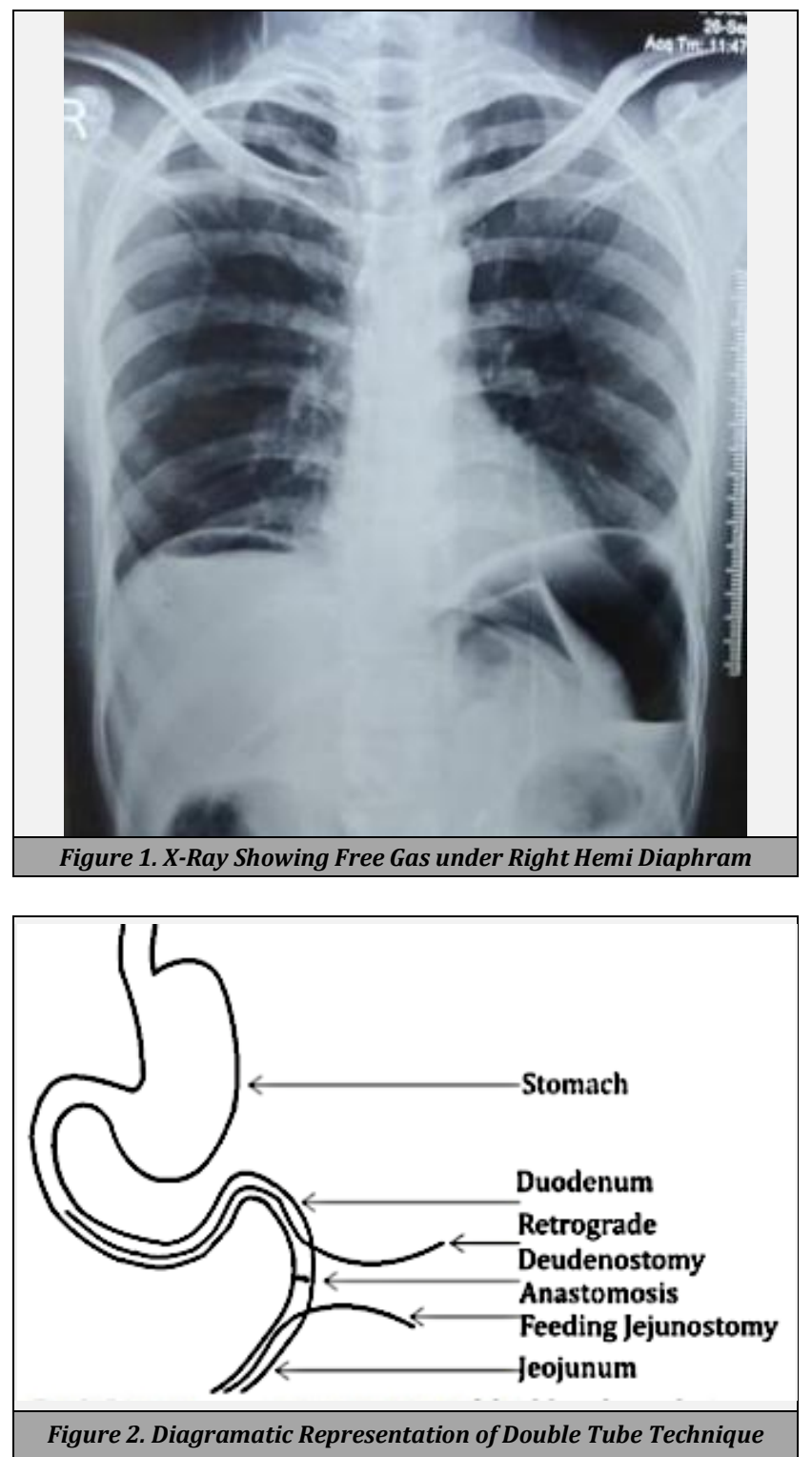

\section{Novel Technique}

In view of gross oedema and contamination to forestall the risk of anastomotic leak and to avoid proximal stoma, a novel technique was devised. Double tube drainage was done, where in a retrograde duodenostomy (RD) proximal to resection anastomosis (RA) and a feeding jejunostomy (FJ) was done distal to the resection anastomosis (fig. 2.a). The patient was started on FJ feed on return of bowel sounds. Furthermore, the duodenostomy output was collected in a especially designed collection bag available commercially and replaced back through FJ tube to enteral circulation (fig. 2.b) Thus, utilizing the gastric, hepatic and pancreatic juices.

The patient was discharged on POD 8 with the tube in situ and was in regular follow-up. After 7 weeks the tubes were removed first FJ tube followed by RD tube. The post-operative period being uneventful.

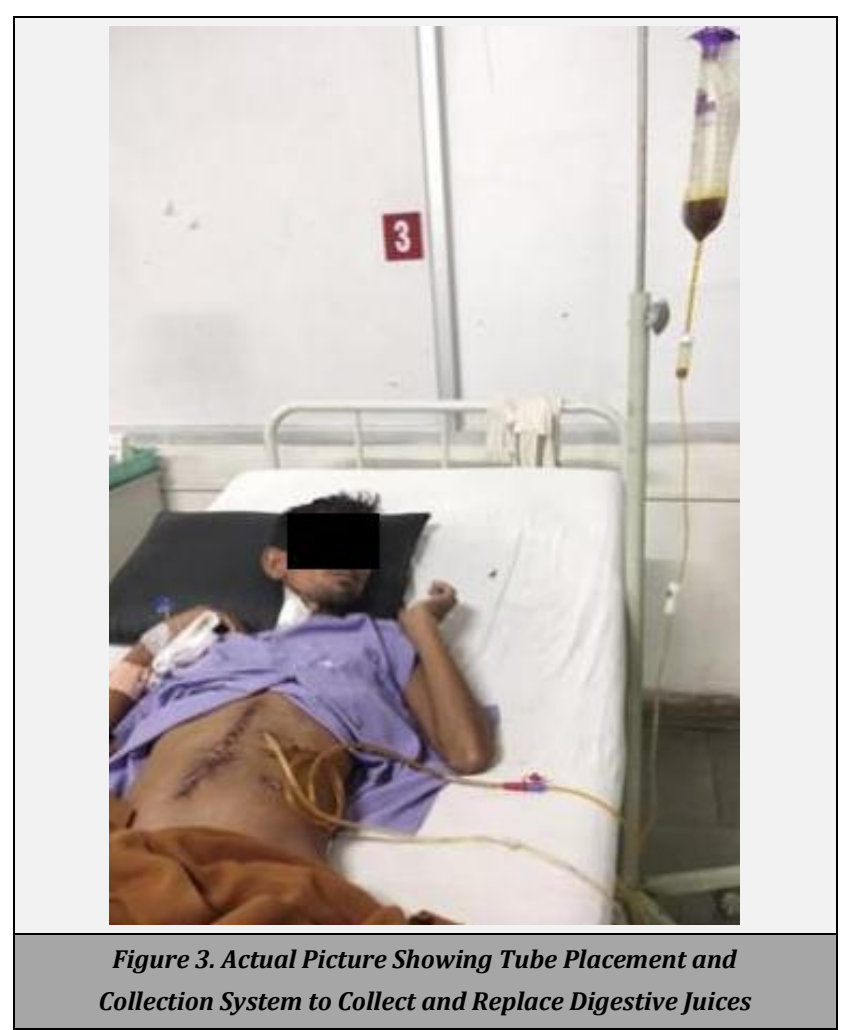

DISCUSSION

Isolated Jejunal perforation is seldom seen in cases of blunt trauma abdomen to the tune of $<1 \%$. ${ }^{\text {[2] }}$ To prevent morbidity and mortality associated with such injuries one needs to have high index of suspicion and frequent detailed examinations. ${ }^{[3]}$ The dynamics of isolated jejunal injury can be attributed to compression of bowel between vertebral column and hard surface with which the patient collides, or may be due to sudden increase in intra-luminal pressures. ${ }^{[4]}$ CECT scan forms the gold standard investigation to assess such blunt trauma patients as it has sensitivity of $92 \%$, specificity of $94 \%$, positive predictive value of $30 \%$ and negative predictive value of $100 \%{ }^{[4]}$ The grading of small bowel injury is done according the AAST.[1] About $13 \%$ of the blunt trauma abdomen or fall from height patients suffer from intra-abdominal organ injury, where bowel comes second to spleen and liver injuries.[5] The amount of time wasted in forming diagnosis can drastically increase the morbidity and thus morbidity.

\begin{tabular}{|c|c|}
\hline Grade & Description \\
\hline Grade I & $\begin{array}{c}\text { Contusion or hematoma without devascularization; partial -thickness } \\
\text { laceration }\end{array}$ \\
\hline Grade II & Full thickness laceration $<50 \%$ of circumference \\
\hline Grade III & Full thickness laceration $>50 \%$ of circumference \\
\hline Grade IV & Transection \\
\hline \multicolumn{2}{|c|}{ Table 1. Grades of Hollow Viscus Injury } \\
\hline
\end{tabular}


Cases of proximal jejunal injuries can be managed by placement of two tubes, viz. Retrograde Duodenostomy and Feeding Jejunostomy. The bile collected from the Retrograde Duodenostomy tube was further utilized and replaced to the patient, thus alleviating the need for total parenteral nutrition also. This reduces the financial burden on the patient. This technique is easily reproducible and can be performed at small centers also. This, although increases the duration of hospital stay, avoids the anastomotic leak and further complications that follow.

Financial or Other Competing Interests: None.

\section{REFERENCES}

[1] Moore EE, Cogbill TH, Malangoni MA, et al. Organ injury scaling, II: pancreas, duodenum, small bowel, colon, and rectum. J Trauma 1990;30(11):1427-9.
[2] Allen GS, Moore FA, Cox CS, et al. Hollow visceral injury and blunt trauma. J Trauma 1998;45(1):69-78.

[3] Munshi IA, DiRocco JD, Khachi G. Isolated jejunal perforation after blunt thoracoabdominal trauma. J Emerg Med 2006;30(4):393-5.

[4] Robbs JV, Moore SW, Pillay SP. Blunt abdominal trauma with jejunal injury: a review. J Trauma 1980;20(4):30811.

[5] Nishijima DK, Simel DL, Wisner DH, et al. Does this adult patient have a blunt intra-abdominal injury? JAMA 2012;307(14):1517-27. 